\title{
A gula de Flusser e o futuro ultratecnológico da comida: entre a ficção científica e a ciência ficcional
}

\section{Antonio Hélio Junqueira}

Doutor; Consejo Latinoamericano de Ciencias Sociales, SP, Brasil. helio@hortica.com.br

\begin{abstract}
Resumo
O artigo discute representações midiáticas da tecnologia enquanto elemento estruturante da sociedade do consumo neoliberal contemporânea à luz do pensamento flusseriano. Toma, por ponto de partida, a análise do texto Da gula, publicado originalmente pelo autor no jornal O Estado de São Paulo, em 1963. O objeto empírico escolhido para esse percurso é o imaginário social sobre o futuro da comida, no âmbito do qual a tecnologia assume diferentes perspectivas, que vão desde a denúncia do seu papel na exaustão dos recursos naturais e do comprometimento da sobrevivência humana, até a superação das mazelas do capitalismo industrial pela reinvenção laboratorial de novos alimentos. O corpus é composto por matérias jornalísticas que foram capas de revista de diferentes gêneros no ano de 2019, das quais os excertos extraídos são analisados com o suporte teórico-metodológico da análise do discurso. Explorando visões da tecnociência como dispositivo autônomo e irrefreável de produção do desenvolvimento, segundo suas próprias dinâmicas e racionalidades, o artigo problematiza as possibilidades de regulação social do progresso tecnológico no âmbito de uma ética tecnológica para o futuro.
\end{abstract}

\section{Palavras-chave}

Comunicação. Discurso científico. Ficção filosófica. Tecnologia. Natureza.

\section{Introdução}

Nos seus escritos - reconhecidos como de grande originalidade e de interesse filosófico crescente em âmbito internacional -, Vilém Flusser (1920-1991) dedicou um instigante espaço à discussão da gula, entendendo-a enquanto metáfora do desejo humano irrefreado de devoração da natureza e do mundo. Essa sua abordagem se concretizou, de 
fato, em artigo publicado no suplemento literário do jornal 0 Estado de São Paulo, de sete de dezembro de 1963, com o título de Da gula. Nele, o pensador explora jogos de sentidos entre as palavras fome e gula, propondo o que denominou de uma "filosofia da gula", no âmbito da qual inscreve "[...] a angústia e o nojo existencial característicos de nossa época [...]" (FLUSSER, 1963, p. 41).

A retomada desse texto flusseriano no contexto pandêmico contemporâneo - em que se inserem tanto a sindemia global que agrega, simultaneamente, as epidemias da obesidade, da desnutrição e da mudança climática (THE LANCET COMMISSIONS, 2019b), quanto a crise do coronavírus (covid-19) - justifica-se especialmente pelo status que o autor confere ao papel social da tecnologia, enquanto inextricável dispositivo de dominação socioambiental, glutonaria e poluição. No contexto desse discurso, a tecnociência é pensada sempre como agente do "progresso", porém pervertida, posto que repleto de riscos se liberada dos compromissos com uma ética tecnológica para com a natureza e a própria humanidade (JONAS, 2015).

Para Flusser (1963, p. 41), é o próprio desenvolvimento científico-tecnológico que conduz a transição humana de uma "economia da fome" para uma "economia da gula". Entende o autor que enquanto a fome é intrínseca à existência animal do homem na engrenagem da vida, a gula é uma perversão que vem permitir a superação dessa sua condição biofisiológica. A fome clama por saciedade e sossego, ao passo que a gula se instaura implacável, devoradora insaciável, engendrando seu moto-perpétuo de destruição de tudo, até mesmo de seu próprio futuro. "A gula é um pecado. É uma perversão da fome [...]" (FLUSSER, 1963, p. 41).

Seguindo o pensamento inspirado de Flusser, vamos encontrar aí esboços ou rudimentos filosóficos para o entendimento da ganância, em seus efeitos devastadores sobre a natureza, a sociedade e a própria alma humana. Para o autor, a gula "[...] em vez de integrar o homem na engrenagem da vida, aliena o homem da vida [...]" (FLUSSER, 1963, p. 41); “[...] a gula humana devora primeiro aquilo que lhe é dado, e depois, insaciável, aquilo que evacuou [...]" (FLUSSER, 1963, p.41).

$\mathrm{Na}$ interpretação desse citado texto de Flusser, Norval Baitello Junior (2010) reconhece o surgimento do que viria a ser um dos pontos-chave do pensamento flusseriano, qual seja o da inversão sujeito-objeto que, no âmbito desse seu artigo, vai encontrar um homem insaciável, que tudo devora, incorpora e dejeta para acabar, ao final, devorado por seus próprios excrementos, simbolicamente confundidos com os aparatos de um parque tecnológico-industrial planetário, irrefreável e insone. 
Não é difícil perceber o quão pertinente pode ser a transposição metafórica da gula para a representação das racionalidades e astúcias do capitalismo contemporâneo, que lhe impelem à subordinação da natureza e do Outro a elementos permanentemente disponíveis para a sua incontrolável devoração (ADORNO; HORKHEIMER, 1985). Nem, tampouco, para a da sociedade de consumo, que resulta dessa relação, e da qual sobram excrementos, lixo e poluição em larga escala, impossíveis de serem consumidos pelo próprio sistema que os produz incansavelmente (BAUMAN, 2008). Assim, amparada pelos dispositivos tecnológicos sempre mais avançados e produtivos, a gula destrói o mundo por suas duas portas: a boca e o ânus.

Emerge, dessa figuração, uma sociedade do consumo problematizada pelo esvaziamento do consumidor enquanto sujeito. Esvaziamento, esse, que é feito pela transposição da carência humana, essencialmente centrada em sua dimensão fisiológica, enquanto expressão da fome, para a da insaciedade da gula, que se consolida no vazio existencial de indivíduos assujeitados (BAITELLO JUNIOR, 2010), sequer capazes de consumir todos os produtos da devoração socioambiental, da qual participam.

O cenário desolador que emerge dessa provocação flusseriana é o mesmo que habita os mais sombrios relatos das catástrofes atuais ou projetadas (STENGERS, 2015) e que estão presentes nos textos jornalísticos, na ficção científica e também na imaginativa ciência do futuro. Trata-se da constatação evidente dos riscos a que estão submetidas a própria humanidade e a natureza, frente a ainda frágeis caminhos que se desenham para a projeção de um futuro possível (REES, 2003). Conflitam-se aí, por um lado a confiança na providência inesgotável da ciência e da técnica na sustentação do status quo da gula e, por outro, a busca determinada de uma alternativa a ela, conforme defendido por Flusser (1963).

A crença e a esperança em um futuro harmônico entre natureza e humanidade, a partir da superação da técnica e do modo de pensar científico atual, bem como da "regulamentação consciente do progresso tecnológico" (TOFFLER, 1972, p. 357), move pensadores e cientistas há décadas. Castoriadis (1975, p. 263), por exemplo, em seu inspirado texto "Técnica", escrito em 1973, propõe pensar a tecnociência do futuro como agente de transformação radical da cultura humana e da sociedade existente, que se fará “[...] junto com uma mudança das significações estabelecidas, dos quadros da racionalidade, da ciência dos últimos séculos e da tecnologia que lhes é homogênea [...]".

Esse duplo caminho de possibilidades é explorado no presente artigo, a partir da seleção e análise de um conjunto de textos jornalísticos sobre o futuro da alimentação planetária, elemento que pode ser considerado emblemático das emergências e desafios que 
configuram o Antropoceno (THE LANCET COMMISIONS, 2019a). A investigação conduzida transita pelos limites porosos e interconectados entre os discursos constitutivos da ficção científica, por um lado, e os da que poderia ser denominada, no âmbito da filosofia de Flusser, uma ciência ficcional ou imaginativa. A proposição se justifica, haja vista que "[...] no cerne do projeto flusseriano, encontra-se um questionamento sobre a condição ficcional de todo discurso, especialmente do discurso científico [...]" (CALDERÓN, 2012, p. 1).

\section{0 corpus da pesquisa e o método}

O corpus da pesquisa foi construído a partir do mapeamento, identificação e seleção de um conjunto de matérias que foram capas de revistas de grande circulação popular no mercado brasileiro no ano de 2019 e que tiveram por tema a discussão sobre o futuro da comida. Foram coletadas publicações de diferentes segmentos, tais como: divulgação científica, economia e negócios, saúde e comportamento. 0 motivo da escolha de 2019 foi que, naquele ano, praticamente todas as revistas dessas categorias abordaram, em uma ou mais de suas edições, a temática em análise, tendo sido muitas delas seguramente inspiradas em suas congêneres internacionais.

Dos textos jornalísticos, foram extraídos excertos relevantes, posteriormente analisados com o apoio dos pressupostos teórico-metodológicos da análise do discurso. A abordagem, em sua vertente da linha francesa (ADF), conforme fundamentos erigidos por Michel Pêcheux (1983), ao final dos anos 1960, e expandida internacionalmente por autores como Foucault $(1996,2004)$ e Courtine (2009) e, no Brasil, por pesquisadores como Gregolin (2007) e Brait (2008), foi escolhida para o percurso desse artigo por sua aptidão e adequação à discussão e entendimento das dimensões políticas dos enunciados discursivos na produção social dos sentidos e de efeitos de verdade, dos quais se nutrem e sob os quais se fundamentam tanto a produção, quanto a circulação e o consumo dos discursos científicos e tecnológicos como os estudados no presente corpus. A análise do discurso contempla e reinstala, nos próprios limites dos textos, as relações sócio-históricas das condições de sua produção, evidenciando implicações entre os interlocutores, entre outros textos (intertextualidade) e entre eles e as implicitações, ou seja, as relações entre o dito e o não dito. Tais características inscrevem opacidade e não transparência aos textos, estabelecendo possibilidades para a emergência de leituras polissêmicas, em que sentidos são gerados tanto por paráfrases (o uso do outro no um, da repetição) quanto metáforas (o 
uso do um, do diferente, no mesmo). Ambas dinâmicas semiológicas são analisadas ao longo do texto que segue.

Os excertos selecionados aparecem recuados no texto, aglutinados segundo categorias de abordagens temáticas comuns, separados por ponto e vírgula e identificados por seus autores, conforme notações descritas no Quadro 1 seguinte.

Quadro 1. Corpus da pesquisa.

\begin{tabular}{|c|c|c|c|}
\hline $\begin{array}{l}\text { Veículo, } \\
\text { periodicidade, } \\
\text { editora e citação no } \\
\text { texto }\end{array}$ & Edição & Data & Título e chamada de capa \\
\hline $\begin{array}{l}\text { Dinheiro Rural } \\
\text { (Mensal) } \\
\text { Editora Três } \\
\text { (MOITINHO, 2019) }\end{array}$ & $\begin{array}{l}\text { Ano 15, } \\
\text { n. }-171\end{array}$ & jul./2019 & $\begin{array}{l}\text { "A era dos alimentos de laboratório". } \\
\text { Hambúrguer à base de ervilha, carnes } \\
\text { vegetais, filés feitos com células de boi. Tudo } \\
\text { isso já é realidade e faz parte de um negócio } \\
\text { que deve movimentar mais de US\$ } 1 \text { trilhão } \\
\text { nas próximas décadas. }\end{array}$ \\
\hline $\begin{array}{l}\text { Exame } \\
\text { (Quinzenal) } \\
\text { Editora Abril } \\
\text { (FILIPPE; BOMFIM, } \\
\text { 2019) }\end{array}$ & $\begin{array}{l}\text { Ano } 53 \\
\text { n. }-1193\end{array}$ & set./2019 & $\begin{array}{l}\text { "A reinvenção da comida". Carne sintética, } \\
\text { superalimentos, ingredientes modificados, } \\
\text { produtos orgânicos, com menos gordura, } \\
\text { açúcar e sal. Novas tendências de consumo } \\
\text { começam a provocar uma revolução na } \\
\text { indústria de alimentos em todo o mundo }\end{array}$ \\
\hline 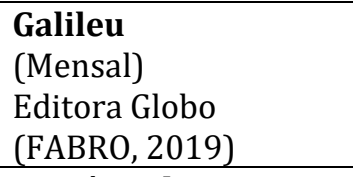 & n. $\stackrel{0}{3} 38$ & set./2019 & $\begin{array}{l}\text { "É de comer!" Alimentos criados em } \\
\text { laboratório, sem a morte de animais, } \\
\text { prometem um futuro sustentável. Será? }\end{array}$ \\
\hline $\begin{array}{l}\text { Isto é Dinheiro } \\
\text { (Semanal) } \\
\text { Editora Três } \\
\text { (VALIM, 2019) }\end{array}$ & $\begin{array}{l}\text { Ano 20, } \\
\text { n. }-1104\end{array}$ & jan./2019 & $\begin{array}{l}\text { "As gigantes aderem à revolução vegana". } \\
\text { Desafiadas pelos novos hábitos alimentares, } \\
\text { empresas como BRF, Nestlé, Burger King e } \\
\text { McDonald's investem em alternativas à } \\
\text { proteína animal. }\end{array}$ \\
\hline $\begin{array}{l}\text { Planeta } \\
\text { (Mensal) } \\
\text { Editora Três } \\
\text { (EQUIPE, 2019) }\end{array}$ & $\begin{array}{l}\text { Ano } 48 \\
\text { n. }-547\end{array}$ & mai./2019 & $\begin{array}{l}\text { "Os veganos vão salvar o planeta?". No } \\
\text { desafio de alimentar a humanidade no século } \\
21 \text { preservando a Terra, dietas baseadas em } \\
\text { produtos de origem vegetal saem na frente. } \\
\text { Mas especialistas ainda não excluem a } \\
\text { proteína animal. Saiba o que se pode comer } \\
\text { sem prejudicar o planeta. }\end{array}$ \\
\hline $\begin{array}{l}\text { Saúde } \\
\text { (Mensal) } \\
\text { Editora Globo } \\
\text { (MANARINI, 2019) }\end{array}$ & n. -448 & out./2019 & $\begin{array}{l}\text { "A dieta que salva você e o planeta". Sua } \\
\text { saúde e o meio ambiente estão conectados. E } \\
\text { com certas mudanças no cardápio podemos } \\
\text { garantir um futuro melhor. }\end{array}$ \\
\hline $\begin{array}{l}\text { Superinteressante } \\
\text { (Mensal) } \\
\text { Editora Abril. } \\
\text { (GARATTONI, 2019). }\end{array}$ & n. -402 & mai./2019 & $\begin{array}{l}\text { "O futuro da comida". Bacon fit, trigo sem } \\
\text { glúten, salmão a preço de tilápia, batata frita } \\
\text { mais saudável. Veja o que a indústria } \\
\text { alimentícia promete colocar na sua mesa. }\end{array}$ \\
\hline
\end{tabular}

Fonte: Elaborado pelo autor. 


\section{Entre o futuro da comida e a comida do futuro}

Representações imaginárias do futuro, quer livremente conduzidas, quer suportadas por criteriosas - mas quiçá igualmente fantasiosas - técnicas e ferramentas preditivas e análises prospectivas da realidade e do mundo, seguem historicamente povoando a mente humana. Futurologistas costumam ocupar lugar de destaque na literatura, na academia e no marketing e muitos deles se tornam, em seu tempo e em seus respectivos campos, bestsellers, autoridades e/ou celebridades.

A representação imaginária do futuro da comida e também da comida do futuro, de um modo ou de outro, sempre fez parte desse universo projetivo. A alimentação de astronautas, de populações ou viajantes interplanetários, por exemplo, inúmeras vezes ocupou, e ainda segue ocupando, a imaginação não apenas de artistas, escritores e público, mas também de cientistas e engenheiros de alimentos, geneticistas, biólogos, médicos e nutricionistas, entre outros profissionais. Assim, certo imaginário eternamente confiante na inesgotável criatividade e nos progressos ilimitados da ciência e da tecnologia aplicada à comida coloniza não apenas a ficção e a mídia, mas se instala, também, nos laboratórios e centros de pesquisa públicos e privados em todo o mundo.

Por outro lado, processos imaginativos da mesma natureza daqueles que suportam tais ensaios e projeções se voltam, também, para a vida cotidiana, na busca de encontrar soluções simplificadoras da existência e promotoras de felicidade doméstica, como, por exemplo, os alimentos oferecidos em saborosas e práticas pílulas concentradas ou em tablets-refeição, que se tornaram emblemáticos nos desenhos animados da família Jetsons, produzidos por William Hanna e Joseph Barbera, e exibidos mundialmente desde o início dos anos 1960. Nessa direção, a moderna tecnologia laboratorial objetiva encontrar não apenas substitutos mais saudáveis ou convincentemente mimetizadores dos alimentos tradicionais, mas também ofertas surpreendentes de itens migrantes da própria ficção científica:

\footnotetext{
Mas não é só de comidas com cara de triviais que viveremos quando todas essas tecnologias estiverem à mesa. Se depender de alguns startups, alimentos ultratecnológicos e com aparência 'diferentona' também vão mudar o que as futuras geração comerão [...](FABRO, 2019, p. 31); A comida que chega à mesa do brasileiro não vem só do pasto [...], mas também é produzida em laboratório, fazendo surgir alimentos jamais imaginados por nossos avós [...] (MOITINHO, 2019, p. 40); Mas parece claro que a reinvenção do que comemos - ou do que a indústria nos
} 
oferece como alimento - é um caminho sem volta [...] (FILLIPE; BOMFIM, 2019, p. 29).

Nos excertos alinhavados, observamos o movimento de práticas discursivas emergentes, no interior das quais noções, conceitos e temas tecnocientíficos de um determinado momento histórico (comida de laboratório, alimentos reinventados e ultratecnológicos) passam a adquirir estatuto de uma nova "verdade" (GREGOLIN, 2007, p. 15) e a serem, assim, enunciados e postos em circulação. Trata-se, em síntese, da consolidação da "vontade de verdade" (GREGOLIN, 2007, p. 17) de certas parcelas da sociedade, que, em tais dispositivos, afirmam e reconfirmam seu poder de mando e orientação dos rumos do desenvolvimento.

Não é fenômeno de difícil entendimento o fato de as imaginações terem se tornado historicamente mais atentas e preocupadas com o futuro dos alimentos e da própria sobrevivência da humanidade, a partir das sombrias projeções feitas pelo economista britânico Thomas Malthus já no longínquo ano de 1798. Pelos seus vaticínios, o colapso humano adviria do fato de as populações crescerem desproporcionalmente em relação à oferta dos alimentos. Desde então, os discursos científicos e tecnológicos passaram a ocupar grande espaço social e notável destaque midiático para convencer a humanidade de que suas conquistas seriam sempre capazes de garantir a oferta abundante de alimentos, quer pelo aumento da produtividade da natureza, quer pela invenção genética de novos animais e plantas ou, ainda, de projetos industriais totalmente independentes dos ciclos, condicionantes e limitações da vida natural.

Se, em um primeiro momento, o crescimento da produtividade agropecuária e a intensa inovação na agroindústria - sobretudo capitaneadas pela dita "Revolução Verde", inaugurada nos primórdios dos anos 1960 - foram capazes de angariar certo nível de confiança no futuro e desmistificar as catastróficas projeções malthusianas anteriores, nas décadas seguintes, contudo, as condições de exploração capitalista desenfreada dos recursos naturais, o aumento do uso de insumos poluentes e a incomensurável geração de lixo residual voltou a atormentar as mentes humanas (GORE, 1993; REES, 2003; GIDDENS, 2010; KLEIN, 2014; STENGERS, 2015).

Nesse contexto e a despeito de a humanidade encontrar-se à beira de uma verdadeira catástrofe ecoplanetária, a discursividade tecnocientífica segue construindo e reconstruindo seu lugar social de arrimo central dos dispositivos ideológicos positivistas e 
pragmáticos da produção da existência, à custa da refutação de toda especulação metafísica, a qual, aliás, considera totalmente inútil e perfeitamente descartável (SFEZ, 1996).

Domina, nesse contexto, certo cientificismo tecnológico focado em apresentar, como conquistas de valor substancial e inquestionável, soluções para os problemas criados pelo próprio sistema sócio-produtivo que os engendra incansavelmente (JUNQUEIRA, 2018). A tecnociência e seus discursos constitutivos são reconvocados ao papel de artífices do caminho humano em direção ao seu progresso ininterrupto e moralmente inquestionável, oferecendo sempre as mais inovadoras e futurísticas soluções a um mundo exaurido, injusto e desigual.

Em sentido contrário e afastando-se dos perigos dessa tecnociência, novas proposições para o pensar e o saber contemporâneos vêm abrir passagem para a emergência social de novas possibilidades políticas do imaginário, as quais comportam e reinscrevem utopias e revoluções. Diferentes autores vêm apontando, de fato, para um recente avivamento do papel da especulação e da imaginação não apenas nos domínios da ciência, mas também no campo filosófico, dos quais tais faculdades humanas foram decididamente afastadas desde o Iluminismo e dos prenúncios da modernidade. Flusser afilia-se a essas tendências de pensamento e inaugura certa "zona cinzenta" no interior da qual "[...] as distinções claras entre saber e ficção já não seriam mais possíveis [...]" (FELINTO, 2016, p. 21).

\section{Da ficção científica à ciência ficcional}

O termo ficção científica (science fiction) foi cunhado pelo inventor, escritor e editor Hugo Gernsback em 1929. Seu emprego se generalizou para a designação de um gênero bastante peculiar de narrativa, na qual a ciência e a técnica são elementos enredados em textos sustentados pela verossimilhança e diegese criadas e articuladas por seus próprios autores. Outros mundos possíveis são aí sugeridos sem que isso venha, contudo, acarretar crença ou descrença, dúvida ou certeza, sobre dados objetivos, comprovados ou não, pela ciência e pela técnica.

Por outro lado, pensadores contemporâneos parecem sugerir uma possível inversão do termo ficção científica (science fiction) para admitir a possibilidade do (res)surgimento de uma ciência ficcional (fictional science), cuja significação apontaria, então, para o retorno potencial à imaginação utópica, à fabulação "pós-moderna" de Lyotard e ao reencontro entre ciência e poesia (RORTY, 1993; SFEZ, 1994, 1996). É também nesse sentido que se pode 
citar Felinto (2016, p. 23), quando destaca que “[...] a ficção filosófica de Flusser realiza algo que poderíamos definir como uma epistemologia fabulatória, estratégia de aproximação da verdade pela via do falso e do ficcional, valorizando as afirmações contraintuitivas e o poder do espanto [...]".

Tradicionalmente, a ficção científica possui, entre seus principais alicerces, as utopias construídas em torno da dominação da natureza pela ciência e pela técnica a favor do desenvolvimento humano e da sua mais completa realização e felicidade terrenas. Projeta, nesse sentido, a superação das doenças, da miséria e de todo tipo de carência, especialmente da fome. Assim, essa categoria de expressão artística reinscreve e sustenta os discursos e as crenças do Iluminismo, ainda que nos contextos do desencanto da modernidade tardia.

No seu interior, contudo, se instauram igualmente narrativas distópicas do futuro forjado por catástrofes ambientais de dimensões planetárias em que textos ecoapocalípticos vêm expressando relevância crescente. Nesse cenário, se consolidam subgêneros específicos como, por exemplo, o das ficções climáticas associadas ao aquecimento global, conhecidas por cli-fi no jargão do jornalismo literário. É nesse novo contexto que narrativas complexas e capazes de unir catastrofismo ecoambiental a sociedades dominadas por poderes totalitários, como vistas na literatura da canadense Margaret Atwood (The Handmaid's Tale, 1985; Oryx and Crake, 2003; The Testaments, 2019), dão continuidade e aprofundam grandes marcos da literatura da ficção científica internacional, como Brave new world, de Aldous Huxley (1932) e 1984 de George Orwell (1949).

Outros autores também se inscrevem nessa vertente, especialmente o norteamericano Kim Stanley Robinson (Nova York 2140, 2017), que destaca o papel deletério das práticas financeiras predatórias nas sociedades capitalistas contemporâneas, Cormack McCarthy (A Estrada, 2007), que inclui a fome e o canibalismo no cenário pós-apocalíptico de seus escritos e Ian McEwan (Solar, 2010), capaz de agregar sátira e causticidade às vaidades e frivolidades humanas mesmo frente às reais dimensões das piores catástrofes.

\section{0 imaginário do futuro da comida em capas de revistas brasileiras}

No campo comunicacional, as análises discursivas de capas de revistas são recorrentes, sendo consideradas, elas próprias, gênero específico do discurso (FARENCENA; PEREIRA, 2005), haja vista que agregam seus elementos constituintes essenciais: tema, estilo e composição (BAKHTIN, 2011). As capas de revista medeiam relações e contratos de 
leitura entre empresas e receptores, interpondo possíveis interpretações dos fatos e a oferta intencionalmente seletiva de informações, segundo critérios editoriais próprios de cada veículo. No bios midiático contemporâneo (SODRÉ, 2002), os textos e imagens componentes das capas de revistas participam discursivamente da oferta fragmentada dos sentidos sociais, disputando lugar nos movimentos ideológicos da construção da hegemonia, dos sujeitos e das identidades (BRAIT, 2008). Os meios de comunicação, ao colocarem em circulação enunciados como os contidos nas capas das revistas selecionadas e que "[...] regulamentam as formas de ser e agir, realizam um agenciamento coletivo de enunciação, entrecruzando determinações coletivas sociais, econômicas, tecnológicas etc." (GREGOLIN, 2007, p. 21).

No conjunto dos textos analisados, selecionados a partir de matérias que foram também capas de revistas, o cenário que sustenta e justifica a produção ultratecnológica de alimentos é fundamentalmente construído pelas sombrias projeções de organizações como The United Nations Organization e seu braço agroalimentar, a Food and Agricultural Organization (FAO), a respeito do incerto futuro do planeta sob intensa exploração agropecuária e agroindustrial e frente à implacável demanda de se ter que alimentar uma população que deverá atingir dez bilhões de pessoas em 2050 (ELBEHRI, 2015). Outro traço comum aos artigos selecionados é a recorrente citação de estudos realizados por pesquisadores reunidos pela publicação científica inglesa The Lancet (2019a; 2019b) e do Oxford Martin Programme on the Future of Food, da Universidade de Oxford, em que uma substancial redução no consumo de carne vermelha é apontada como medida urgente e necessária tanto para o alívio da pressão agropecuária sobre as condições climáticas e ambientais, em escala planetária, quanto para a melhoria da saúde e da dietética humanas (SPRINGMANN et al, 2016). Tais afirmações se constatam em excertos selecionados como:

Hora de virar a mesa. 0 impacto da produção de alimentos no meio ambiente é um aspecto determinante para a sobrevivência da raça humana e do planeta no século 21. Boa parte da solução está em cortar a própria carne [...] (EQUIPE...,2019, p.30); sua saúde e o meio ambiente estão conectados. E com certas mudanças no cardápio podemos garantir um futuro melhor [...] (MANARINI, 2019).

A operação discursiva que aí podemos prontamente reconhecer é aquela que institui a intertextualidade conectiva e agenciadora da enunciação coletiva, que se torna, assim, capaz de assegurar que a migração dos textos tecnológicos e científicos para o campo dos textos jornalísticos adquiram uma materialidade repetível (FOUCAULT, 2004) e 
ilusoriamente una no corpo social. Estando, pois, em seu próprio papel, a mídia ecoa vozes e discursos que vindos de outros lugares da sociedade, promovem a construção de novas subjetividades, a repetição de conceitos e ideias e a construção de novos consensos.

No contexto midiático estudado e em resposta aos desafios desenhados, prevalece um discurso entusiasmado a respeito do papel e da incansável habilidade da agroindústria em desenvolver e ofertar ao mercado soluções inovadoras e cada vez mais surpreendentes em alimentos. Certo tom de euforia contamina a elaboração de complexas e detalhadas listas de alimentos, aumentadas a cada nova matéria publicada: proteínas animais sintéticas produzidas laboratorialmente a partir de células originais (cell-based), hambúrgueres e outros produtos miméticos da carne vermelha elaborados à base de vegetais (plant-based), ingredientes geneticamente modificados, "superalimentos" e assim por diante.

Essa expressa necessidade de catalogar, codificar e relacionar de forma completa e exaustiva listagens de possibilidades e resultados, parece cumprir a exata função iluminista da vontade de domínio e controle sobre totalidade do conhecimento do mundo, cujo processo vertiginoso já foi sugerido por Eco (2010). Nesse sentido, os textos selecionados, ao longo da maior parte da sua estrutura, incluindo as chamadas de capas já destacadas no Quadro 1, reiteram a visão pragmática e produtivista da tecnociência posta a serviço do capitalismo neoliberal contemporâneo, convocando discursivamente os efeitos da maravilha e do encantamento de suas virtudes criativas e redentoras:

\begin{abstract}
Carne sintética. Ingredientes modificados. Leite, queijo e maionese que parecem de verdade, mas não são. Alternativas a gordura, açúcar e sal. Diante de novos hábitos, uma mudança radical na indústria de alimentos é um caminho sem volta [...] (FILLIPE; BOMFIM, 2019, p. 16); Hambúrguer vermelhinho, suculento, saboroso, mas nenhum animal precisou morrer para saciar a fome. A batata frita, macia por dentro e crocante por fora, pode ter vários tipos de design, porque é moldada em impressora 3D [...] sushis que não são feitos de peixe preparados sob medida para cada cliente. Cenas de um futuro distante? Se depender de cientistas e startups, será a realidade em breve [...] (FABRO, 2019, p. 26).
\end{abstract}

Discursivamente, a mídia opera a construção de formas simbólicas de uma nova realidade desenhada pela tecnociência alimentar laboratorial, viabilizando renovadas representações das relações entre leitores e consumidores com sua alimentação futura. É, assim, instituída uma "história do presente" que, ao mesmo tempo em que evoca a memória de imagens e palavras enraizadas no passado (leite, queijo, maionese, hambúrguer, batata, sushi) como as conhecemos e representamos, desloca seus sentidos. Os alimentos parecem 
"ser de verdade", mas já não o são mais, posto que sintéticos, elaborados a partir de complexos processos de design e de materiais mimetizadores da natureza reconhecível que vêm reconfigurar o próprio sentido do "natural" (LEVINOVITZ, 2020).

Não se observam, nas abordagens consideradas, interpelações mais amplas e consistentes dos sistemas globais de produção, consumo e distribuição de alimentos, o que vem a negar possibilidades para a emergência da discussão da necessidade de revisão dos modelos alimentares mundiais atualmente prevalecentes. Ainda que nos textos haja menção a problemas ambientais, esses são quase sempre relacionados ao consumo de carne vermelha e aos impactos da pecuária no efeito estufa. Questionamentos sobre estilos de vida, práticas de consumo, solidariedade, empatia social e perversidades distributivas são, assim, discursivamente apagados (PECHÊUX, 1983). Via de regra, apenas duas questões compõem o cenário de fundo para justificar e valorizar a vertiginosa expansão da criatividade da indústria alimentar: a crescente preocupação humana com a saúde e a estética de seu próprio corpo e a opção pelo vegetarianismo ou, na maior parte dos textos, pelo veganismo, como resposta à problemática ecoambiental crescente.

É de comer! Alimentos criados em laboratório, sem a morte de animais, prometem um futuro sustentável. Será? (FABRO, 2019); Estamos na era dos alimentos em abate animais [...] (MOITINHO, 2019, p. 41). 0 fenômeno retrata a velocidade com que novos hábitos começam a remodelar a indústria de alimentos no mundo. No centro das mudanças, um consumidor cada vez mais sensível aos apelos da saudabilidade e sustentabilidade [...] (FILLIPE; BOMFIM, 2019, p. 19).

Note-se, contudo, que se trata nesses casos de um veganismo reificado enquanto hábito de consumo ou prática dietética, esvaziado, portanto, de seu significado filosófico. Os discursos aí mobilizados não se relacionam com o veganismo configurado na interseccionalidade com outros movimentos sociais (COLLINS; BILGE, 2016), como o feminismo (ADAMS, 2015, 2020; RUDY, 2012; NIBERT, 2013), o ecossocialismo e os de denúncia e superação dos dilemas e mazelas do capitalismo neoliberal contemporâneo. Diferentemente do que se retrata no corpus analisado, nessas dimensões, o movimento vegano é articulado, essencialmente, pela condenação moral do especismo, do qual resulta na imposição diferencial de direitos entre as espécies, no tratamento discriminatório, na inferiorização e na dominação entre os seres (PERROTA, 2017). Pensá-lo como mera expressão de estilo de vida, prática de consumo ou de opção alimentar é, pois, ato redutor, inapropriado e impertinente. No entanto, é a ordem do discurso vigente que vem controlar e 
impedir a emergência de novas identidades sociais possíveis, reduzindo a expressão do ativismo vegano:

Outro aspecto estimula as novas tendências de consumo. Com a ampliação do número de consumidores preocupados com o impacto ambiental do que comem, eliminar ou reduzir a frequência de produtos de origem animal na dieta virou quase um ato político [...] (FILIPPE; BOMFIM, 2019, p. 19; grifo nosso).

No corpus analisado, o discurso tecnológico que se constrói é o da ciência capaz de criar, incansavelmente, soluções e aportes tecnológicos ao desenvolvimento de novos produtos e de oferecer "conserto" para os seus próprios estragos, quer sobre o meio ambiente, quer sobre a saúde dos corpos humanos. Trata-se, pois, de uma ciência verdadeiramente positivista, produtivista e pragmática, no âmbito da qual é negada a emergência dos aportes das ciências humanas e sociais que viabilizariam trazer a questão da alimentação e do seu futuro para outras perspectivas éticas e estéticas verdadeiramente revolucionárias. Ao contrário, apoia e reitera a soberania e o reinado inquestionável da gula flusseriana. A vitória técnico-científica desenhada não soma louros pelo combate à desigualdade social no acesso aos alimentos e na revisão dos modos de produção para modelos mais sustentáveis. Seu sucesso é medido e alardeado pelas imensas cifras financeiras mobilizadas por grandes empresas multinacionais e por startups, especialmente as chamadas foodtechs. Do ponto de vista discursivo, o efeito de coerência obtido decorre do agenciamento simbólico de objetos, sujeitos, sentidos, valores e hierarquias que delimitam, classificam, ordenam, controlam e distribuem os próprios discursos legitimadores da ciência e da tecnologia como dispositivos autônomos e irrefreáveis da produção capitalista do desenvolvimento e da existência cotidiana.

Sem carne, com lucro: [...] revolução vegana já movimenta U\$ 50 bilhões ao ano e transforma a indústria mundial [...] Houve, ainda, uma explosão de venda de "leites" alternativos, que subiu de US\$1,5 bilhão a US 5 bilhões entre 2011 e 2016 [...]. Diversas startups criaram inovações importantes e atraíram a atenção de empresas interessadas em não perder o bonde da revolução [...] (VALIM, 2019, p. 33-36); Estima-se que versões veganas e carnes sintéticas representarão 10\% do mercado total de carnes até 2029 [...]. O mercado global de startups de tecnologia no ramo de alimentos já produziu 35 unicórnios - nome dado às que chegam rapidamente à casa do bilhão de dólares de valor de mercado. [...]. Estima-se que 7 bilhões de dólares tenham sido investidos no mundo em 2018 nas chamadas foodtechs [...] (FILLIPE; BOMFIM, 2019, p. 16-27); [...] antes de chamar aquele amigo vegano de "esquisito", lembre-se de que ele é um consumidor disputado pelas maiores empresas do mundo [...] (VALIM, 209, p.37). 
No âmbito da visão tecno-utópica predominante a respeito do futuro da comida, o cenário de ficção científica é criado e insuflado pelo crescente uso da inteligência artificial, da robótica e de tecnologias digitais como as impressões em três dimensões. Na prática, o uso dessas tecnologias e de suas correspondentes ferramentas já é, em parte, realidade no desenvolvimento, por exemplo, de diferentes composições vegetais capazes de simular texturas e aparências semelhantes às dos hambúrgueres e outros produtos de origem animal, a partir de hemoglobinas presentes em raízes da soja e de proteínas da ervilha, do grão de bico e de outros alimentos tradicionais.

Nesse contexto, consumidores despontam assujeitados pela crença no pragmatismo tecnológico e na ciência invencível, capaz de apagar todos os impasses e limites da própria natureza (CRONIN; FITCHETT, 2020). Em sua entusiasmada matéria, Garattoni (2019), por exemplo, recolhe e alinhava depoimentos de diversos pesquisadores, cientistas e empresários sobre as inovações alimentares, que vêm atestar o vigor dessa discursividade enaltecedora da tecnociência, especialmente em relação ao aumento da produtividade dos organismos e à sua capacidade de desenvolvimento de itens considerados "mais saudáveis", por conterem maior índice de nutrientes desejáveis e redução dos elementos considerados nocivos (gorduras, glúten, aditivos etc.):

\begin{abstract}
Mais gostosa, mais saudável - e até mais barata. Modificar geneticamente um produto para torná-lo mais saudável é um conceito interessante" [...] “É o que promete o projeto OpenAg (agricultura aberta) do MIT. Ele está tentando construir food computers - máquinas dentro das quais seria possível reproduzir o clima e as características do solo de qualquer lugar do mundo [...] não apenas simular o clima atual dos lugares, mas projetar o clima do passado e trazer de volta à vida uvas Carbernet do Vale de Napa (Califórnia) de 1982, por exemplo [...] o objetivo é criar uma 'Wikipedia dos fenótipos', em que as receitas serão baixadas e aperfeiçoadas pelos usuários ao redor do mundo"; [...]"Ao contrário de proteínas feitas com soja, amêndoas ou outras plantas, as nossas são exatamente iguais às que vêm da vaca"; [...] "Nós somos cem vezes mais produtivos que a agricultura tradicional na mesma área da terra"; [...]"Eu nem vou tentar explicar, é uma física quântica muito profunda [...]" (GARATTONI, 2019).
\end{abstract}

Os relatos analisados atestam a expansão global do acesso às tecnologias digitais e os intensos processos contemporâneos de inovação, que vêm favorecendo um cenário fértil para pensar a comida do futuro. Não apenas a produção e os modos de obtenção industrial de alimentos estão aí contemplados, mas também os aspectos mais variados da vida doméstica cotidiana. A projeção e oferta de novos equipamentos de cozinha inteligentes passaram a fazer parte do imaginário da internet. 
No entanto, na ausência de uma "ética do futuro", conforme proposta do filósofo Hans Jonas (2015), é deixado à tecnociência futura o encontro das soluções aos problemas, dilemas e desafios que ela própria constantemente cria e recria. É desse círculo vicioso que provém, pois, a incontrolável voracidade devoradora da gula flusseriana que impõe uma “[...] crescentemente impiedosa pilhagem do planeta, até que este pronuncie sua palavra de força e se furte à exigência excessiva [...]" (JONAS, 2015, p. 252).

A imaginativa epistemologia fabulatória de Flusser parece aqui servir aos desejáveis propósitos de recuperação do que ele próprio chamou de uma "economia da justiça poética" (FLUSSER, 1963, p. 41), capaz de reconduzir a humanidade a um "novo estado de ânimo". Isabelle Stengers (2015, p. 140), também alinhada a tal ideário, propõem o desesperado uso da imaginação para a superação das catástrofes que nos ameaçam, posto que "a barbárie é hoje o tristemente previsível". Para ela é necessário, antes de tudo, reconstruir e reaprender "a arte de ter cuidado" (STENGERS, 2015, p. 61).

\section{Considerações finais}

A análise do corpus midiático dessa pesquisa, conforme visto, evidenciou um campo simbólico e comunicativo demarcado pela entusiasmada crença na capacidade da tecnociência em transformar imaginativos produtos assemelhados aos da ficção científica em realidade, conferindo-lhes materialidade, sentido, utilidade e socorro a uma sociedade pandêmica e seriamente ameaçada. Por outro lado, os textos analisados convidam, também, à reflexão e à dúvida se tais capacidades serão, de fato, suficientes para refrear as iminentes catástrofes socioambientais postas em marcha pela sociedade de consumo contemporânea.

Nesse embate, a obra flusseriana sobre os dilemas da gula, ou de uma possível "filosofia da gula", apontam para sua pertinência na reconfiguração ideológica e estética do próprio consumo, do que poderia emergir novos modos éticos de partilhar coletivamente as conquistas tecnológicas do "progresso". Flusser, ao lado de outros notáveis pensadores contemporâneos, permite vislumbrar a oportuna sugestão ou o apelo a uma ética do futuro, conforme originalmente proposta pelo filósofo Hans Jonas (1903-1993), em que um "princípio de moderação" poderia viabilizar novas formas da convivência em um existir ético e solidário para com a humanidade, a natureza e o próprio futuro.

A arte de modo geral e a ficção científica, em especial, parecem servir ao propósito social do oferecimento de sentidos e chaves sígnicas para a interpretação da realidade presente e, principalmente, para a previsão imaginativa do próprio futuro humano. Trata-se, 
nesse sentido, de uma delegação, ao futuro, das ações que poderiam estar em construção individual e coletiva no presente. Há aí, portanto, um adiamento, uma abstenção social da luta pela efetiva construção do futuro no presente, em prol da aposta nos acertos e regulações - de todo incerta e imprevisível - da ciência e da técnica, a partir de suas próprias lógicas e racionalidades desenvolvimentistas.

Parece haver pouca dúvida de que a ficção científica é portadora de largas e significativas contribuições ao pensamento reflexivo a respeito dos dilemas e desafios humanos frente à tecnologia e seu papel na construção da realidade-mundo. No âmbito das narrativas que constrói, ecocatástrofes podem servir aos propósitos de instauração de uma heurística do medo (JONAS, 2015), em que se torna possível enxergar algum benefício da especulação presente dos maus vaticínios e prognósticos sobre o futuro. Por outro lado, ela alimenta, também, a emergência e a sustentação da crença no papel e na contribuição permanente da tecnociência em encontrar soluções para todos os problemas e desgraças humanas. Ambas possibilidades, contudo, pouco ajudam a pensar uma efetiva revolução nos padrões de existência social; algo que nos livre da gula que "nos conduz à destruição de nós mesmos" (FLUSSER, 1963, p. 41).

Em sentido contrário, talvez seja na ciência ficcional que residam as principais esperanças de uma (re) invenção imaginativa do futuro humano em bases sustentáveis e que nos coloque "[...] em um estado de prontidão para uma modificação radical do nosso conceito 'homem [...]'” (FLUSSER, 1963, p. 41).

O imaginário da purificação e da regeneração integral da saúde tanto humana, quanto planetária, em toda a sua magnitude simbólica, constitui-se, quiçá, no último reduto utópico do século 21. Não é possível adentrá-lo, contudo, sem os benefícios cooperativos da ciência e da tecnologia. Resta saber se seremos capazes de trazê-las ao convívio de uma regulação consciente e redefinidora de um novo sentido de progresso, harmônico, equânime e inclusivo.

\section{Referências}

ADAMS, Carol J. The sexual politics of meat: a feminist-vegetarian critical theory. New York: Blomsbury Academic, 2015.

ADAMS, Carol J. The pornography of meat: new and a updated edition. New York: Blomsbury Academic, 2020. 
ADORNO, Theodor; HORKHEIMER, Max. Dialética do esclarecimento. Rio de Janeiro: Jorge Zahar Editor, 1985.

ATWOOD, Margaret. Oryx and Crake. New York: Random House Publishing Group, 2003.

ATWO0D, Margaret. The handmaid's tale. New York: Random House Publishing Group, 1985.

ATWO0D, Margaret. The testaments. New York: Doubleday, 2019.

BAITELLO JUNIOR, Norval. A gula de Flusser: a devoração da natureza e a dissolução da vontade. In: BAITELLO JUNIOR, Norval. A serpente, a maçã e o holograma: esboços para uma teoria da mídia. São Paulo: Paulus, 2010, p. 13-30.

BAKTHIN, Mikhail. Estética da criação verbal. São Paulo: Martins Fontes, 2011.

BAUMAN, Zygmunt. Vida de consumo. Buenos Aires: Fondo de Cultura Económica, 2008.

BRAIT, Beth. Contribuições bakhtinianas para a análise do verbo-visual. In: BASTOS, Neusa Barbosa. (Org.). Língua Portuguesa: lusofonia, memória e diversidade cultural. São Paulo: EDUC/FAPESP, 2008, p. 257-269.

CALDERÓN, Andrea Soto. Juego e imaginación em Vilém Flusser. Flusser Studies, n. 13, mai., 2012.

CASTORIADIS, Cornellius. Encruzilhadas do labirinto/1. São Paulo: Paz e Terra, 1975.

COLLINS, Patrícia Hill; BILGE, Sirma. Intersectionality. Cambridge, UK; Malden, MA: Polity Press, 2016.

COURTINE, Jean-Jacques. Análise do discurso político. 0 discurso comunista endereçado aos cristãos. São Carlos: Edufscar, 2009.

CRONIN, James; FITCHETT, James. Lunch of the last human: nutritionally complete food and the fantasies of market-based progress. Marketing Theory, v. 20, n. 2, abr./ 2020.

ECO, Umberto. A vertigem das listas. Rio de Janeiro: Record, 2010.

ELBEHRI, Aziz (Ed.). Cimate change and food systems: global assessments and implications for food security and trade. Rome: FAO, 2015.

EQUIPE DA REVISTA PLANETA. Os veganos vão salvar o planeta? Planeta, ano 48, n. 547, p. 30-35, mai./2019

FABRO, Nathalia. Do laboratório à mesa. Galileu, n. 338, p. 25-34, set. 2019.

FARENCENA, Gessélda; PEREIRA, Luciara. As especificidades do gênero capa de revista. Ideias, v.21, p. 68-73, 2005. 
FELINTO, Erick. Zona cinzenta: imaginação e epistemologia fabulatória em Vilém Flusser. In: FELINTO, Erick; MÜLLER, Adalberto; MAIA, Alessandra (Orgs.). A vida secreta dos objetos: ecologia das mídias. Rio de Janeiro: Azougue, 2016, p. 11-27.

FILIPPE, Marina; BOMFIM, Murilo. A reinvenção da comida. Exame, ano 53, n. 17, edição 1193, p. 16-29, 18 set. /2019.

FLUSSER, Vilém. Da gula: 0 Estado de São Paulo, Suplemento Literário, p. 41, 7 de dezembro de 1963.

FOUCAULT, Michel. A ordem do discurso. São Paulo: Loyola, 1996.

FOUCAULT, Michel. A arqueologia do saber. Rio de Janeiro: Forense Universitária, 2004.

GARATTONI, Bruno. 0 futuro da comida. Superinteressante, n. 402, p. 20-34, mai./2019.

GIDDENS, Anthony. A política da mudança climática. Rio de Janeiro: Zahar, 2010.

GORE, Albert. A Terra em balanço: ecologia e espírito humano. São Paulo: Augustus, 1993.

GREGOLIN, Maria do Rosário. Análise do discurso e mídia: a (re)produção de identidades. Comunicação, Mídia e Consumo, v. 4, n. 11, p. 11-25, nov. / 2007.

HUXLEY, Aldous. Brave new world. New York: Garden City Publishing Company, 1932.

JONAS, Hans. 0 princípio responsabilidade: ensaio de uma ética para a civilização tecnológica. Rio de Janeiro: Contraponto; Ed. PUC-Rio, 2015.

JUNQUEIRA, Antonio Hélio. A Igreja entra no clima: comunicação, educação e consumo em "Sobre o cuidado da casa comum" - encíclica papal de Francisco. Comunicação, Mídia e Consumo, v. 15, n. 44, p. 583-599, set./dez. 2018.

KLEIN, Naomi. This changes everything: capitalism vs the climate. New York: Simon \& Schuster, 2014.

LEVINOVITZ, Alan. Natural: how faith in nature's goodness leads to harmful fads, unjust laws, and flawed science. Toronto: Penguin Random House, 2020.

MANARINI, Thaís. A dieta que vai salvar você e o planeta. Saúde, n. 48, out. 2019.

MCARTHY, Cormac. A estrada.. Rio de Janeiro: Objetiva, 2007.

MCEWAN, Ian. Solar. New York: Random House Publishing Group, 2010.

MOITINHO, Fábio. A era dos alimentos de laboratório. Dinheiro Rural, ano 15, n, 171, p. 4046, jul./2019.

NIBERT, David Alan. Animal Oppression and Human Violence: domesecration, capitalism, and global conflict. New York: Columbia University Press, 2013. 
ORWELL, George. Nineteen Eighty-Four. London: Secker and Warburg, 1949.

PERROTA, Ana Paula. Ciência e política no ativismo em favor do direito dos animais.

Vivência - Revista de Antropologia, n. 49, p. 13-32, 2017.

PÊCHEUX, Michel. 0 discurso: estrutura ou acontecimento. Campinas: Pontes, 1983.

REES, Martin. Our final hour: a scientist's warning: how terror, error, and environmental disaster threaten humankind's future in this century - on earth and beyond. New York: Basic Books, 2003.

ROBINSON, Kim Stanley. New York 2140. New York: Orbit, 2017.

RORTY, Richard. Conséquences du pragmatism. Paris: Editions du Seuil, 1993.

RUDY, Kathy. Locavores, feminism, and the question of meat. The Journal of American Culture, v. 35, n.1, p. 26-36, feb./ 2012.

SFEZ, Lucien. Crítica da comunicação. São Paulo: Edições Loyola, 1994.

SFEZ, Lucien. A saúde perfeita: crítica de uma nova utopia. São Paulo: Edições Loyola, 1996.

SODRÉ, Muniz. Antropológica do espelho: uma teoria da comunicação linear e em rede. Petrópolis: Vozes, 2002.

SPRINGMANN, Marco; GODFRAY, Charles; RAYNER, Mike; SCARBOROUCH, Peter. Analysis and valuation of the heath and climate change cobenefits of dietary change. Proceedings of the National Academy of Science (PNAS), v. 113, n. 15, p. 4146-4151, April 12, 2016.

STENGERS, Isabelle. No tempo das catástrofes - resistir à barbárie que se aproxima. São Paulo: Cosac Naify, 2015.

THE LANCET COMMISIONS REPORT. Food in the Anthropocene: the EAT-Lancet Commision on healthy diets from sustainable food systems. Lancet, n. 393, p. 47-492, jan. 2019a.

THE LANCET COMMISIONS REPORT. The global syndemic of obesity, undernutrition, and climate change. , v. 393, n. 10.173, p. 791-846, 2019b. TOFFLER, Alvin. O choque do futuro. Rio de Janeiro: Editora Artenova, 1972.

VALIM, Carlos Eduardo. Sem carne, com lucro. Isto é Dinheiro, ano 20, n. 1104, p.32-37, 23 jan,/ 2019. 


\title{
Flusser's gluttony and the ultratechnological future of food: between science fiction and fictional science
}

\begin{abstract}
The article discusses media representations of technology as a structuring element of contemporary neoliberal consumer society in the light of Flusserian thought. It takes, as a starting point, the analysis of the text "Da gula", originally published by the author in the newspaper O Estado de São Paulo, in 1963. The empirical object chosen for this journey is the social imaginary about the future of food, within the scope from which technology takes on different perspectives, ranging from denouncing its role in depleting natural resources and compromising human survival, to overcoming the ills of industrial capitalism by reinventing new foods in the laboratory. The corpus is composed of journalistic articles that were magazine covers of different genres in 2019, from which the excerpts extracted are analyzed with the theoretical and methodological support of discourse analysis. Exploring views of technoscience as an autonomous and unrestrained device for the production of development, according to its own dynamics and rationalities, the article problematizes the possibilities of social regulation of technological progress within the scope of technological ethics for the future.
\end{abstract}

\section{Keywords}

Communication. Scientific discourse. Philosophical fiction. Technology. Nature.

Recebido em 30/04/2020

Aceito em 23/07/2020 